\section{Apresentação}

\title{
Multimodalidade da Memória: Corpo, Narrativa e Teoria Social
}

\section{Edson Farias $^{1}$ e Salete Nery ${ }^{2}$}

compartilham ambiências. A um só turno, tal incorporação, que se dá via socialização, implica a

${ }^{1}$ Pesquisador do CNPq; professor do PPGSOL/UnB e do PPMLS/UESB pesquisador do $\mathrm{CMD} / \mathrm{UnB}$; editor da revista Arquivos do CMD.

Doutora em Ciencias Sociais Doutora em Ciencias Sociais (UFBa). Docente Co Programa de (Uss-Gra). Ly̧a en Ciências Sociais (UFRB). Líder do grupo de Pesquisa Corpo, Socialização e Expressõe Culturais (ECCOS/UFRB) pesquisadora do grupo Cultura Memória e Desenvolvimento $(\mathrm{CMD} / \mathrm{UnB})$.

A persistência das tentativas de definir memória, que remontam à chamada antiguidade clássica, e mesmo o crescimento vertiginoso do interesse pelo tema nos últimos tempos permitem entrever sua complexidade e, em especial, sua importância ao debate acerca do humano. A razão para tanto consiste em que o problema da memória é o mesmo da constituição simbólica do mundo. Neste sentido, pautar a memória é interrogar simultaneamente sobre as condições de possibilidade de um mundo sócio-histórico, isto é, de um mundo herdado e incorporado como uma das dimensões da natureza e do ser/estar do gênero humano, mas a partir de uma série de enquadramentos que foram, pois, sóciohistoricamente se delineando e modulando em função dos instáveis equilíbrios de poder entre seres humanos e na relação destes com os demais seres da natureza, mas também dos objetos com os quais apropriação do coletivo como coisa que respeita às singularidades individuais fazendo com que as fronteiras entre o social e a personalidade sejam mais idealizadas do que efetivas, afrontando os desejos de um mundo plenamente organizado a partir de elementos discretos reciprocamente excludentes ou, ao máximo, complementares. Contudo, uma vez que a memória remete a representações e a um aprendizado coletivo-histórico sobre modos de apresentação de si e de representar, impõe-se a consideração sobre os mecanismos de seleção, nem sempre reflexivos, e as valorações e hierarquizações subjacentes ao memorizar/lembrar/simbolizar, articulados em diferentes modos de pensamento, linguagens e práticas. 
Tais práticas, por sua vez, podem ser associadas aos diferentes fazeres, de objetos a rituais, bem como aos diferentes manejos do corpo nos usos específicos do potencial de disposições que nosso aparato orgânico permite. E aqui se descortina mais um vetor das considerações acerca da memória, o seu caráter de capacidade biológica. Deste modo, somos seres de memória na medida em que aprendemos paulatinamente a fazer uso de certos recursos biológicos que estavam à nossa disposição em potência, o que significa que mesmo o modo de uso desses recursos nada mais é do que uma possibilidade dentre outras. Em outros termos, não apenas o conteúdo daquilo que é lembrado e esquecido tem a marca de um aprendizado social, mas igualmente os mecanismos com os quais operamos a memória; por exemplo, nas mobilizações e sínteses específicas de eventos que entendemos por singulares em sua distribuição num tempo que aprendemos a socialmente esquadrinhar. A problematização que daí se insinua é relativa à natureza simbólica das disposições corporais. Com isto, conforme sugerido por Thais Marinho no artigo que compõe este dossiê, voltada à produção de conhecimentos socioantropológicos, paulatinamente se define uma agenda orientada por um protocolo de pesquisa relativo à questão em torno da tessitura biopsíquica das simbolizações.

Mesmo o incremento nas atenções a respeito da memória em diferentes áreas do conhecimento, e suas reelaborações recentes, acabam por ser tributários de uma transformação crucial nas chaves de compreensão de mundo em direção a uma antropocéia e depois a uma sociodicéia. Uma vez que os destinos humanos são assumidos enquanto decorrência de ações humanas, em lugar da vontade divina, torna-se premente desvendar os mecanismos de acesso ao mundo, isto é, o modo como conferimos inteligibilidade às ações. Simultaneamente, o processo de unificação (político-territorial) dos Estados nacionais terá na construção de uma memória comum (nacional) um elemento de unificação (moral-afetiva) das comunidades; em outros termos, de conformação de identidades marcadas pelo eixo do pertencimento nacional, possibilitando a efetivação de uma moral de paz interna justificada por laços comunais de acento afetivo, entendidos como tradicionais, ainda que às expensas de uma moral externa em grande medida marcada pela concorrência, preconceito e guerras (FARIAS, 2011, p.25-59). $\mathrm{E}$ aquilo que aprendemos a nominar insumos culturais fornecem a base e o fermento fundamental a esse projeto moderno, ao passo em que a demanda por emoções "autênticas" impulsiona a produção e o consumo cultural de matriz chamada popular (ALVES, 2011, p. 447-483).

Assim, memória e cultura se articulam e se transmutam em objeto de interesse político e intelectual de grande envergadura. Nestes termos, a teoria social trouxe, através de diferentes expoentes, o cunho de buscar afirmar e compreender os enquadramentos de mundo como coisa social e que constrói o social, pondo a si própria a difícil tarefa de, sob o signo da busca da 
verdade, tratar de mecanismos nos quais ela mesma está abarcada, enquanto coisa social. Como se efetivam as teorizações sobre o social, que tomam a memória por objeto e, ao mesmo tempo, funcionam a partir de enquadramentos reféns do uso social da memória e do debate sobre memória?

Este dossiê tem por objetivo lançar discussões e reflexões acerca do par memória e teoria social tendo por eixo aquilo que Edson Farias, em seu artigo presente neste dossiê, chama de multimodalidade da memória e, assim, o acionamento do debate sobre memória na teoria social em suas fricções com o conhecimento produzido por outras áreas.

$\mathrm{O}$ artigo de Farias, intitulado Multimodalidade da Memória na Pespectiva da Sociologia dos a Priori Sociais, que encerra esta edição, acaba por ser uma espécie de ponto de articulação e elucidação dos debates dos demais artigos, uma vez que busca perseguir os caminhos mesmo da incorporação e desenvolvimento do tema filosófico do conhecimento no âmbito da sociologia, na forma do tópico dos a priori sociais, e o modo como a compreensão e assunção da dimensão simbólica da linguagem conformou a base para a articulação recente entre conhecimento, memória e corpo. Assim, o texto oferece o pano de fundo que abriga os temas dos demais artigos numa totalidade coesa e nos ajuda a compreender os interesses e olhares sobre a memória à luz da história de conformação da própria teoria social. Assim, anunciam-se os recortes que foram trabalhados nos demais textos, e em outros tantos ausentes deste dossiê, como decorrência desta história, e portanto nela inserida, e abrem-se as frestas dos caminhos pelos quais a sociologia busca avançar.

É deste modo que, a partir da proposta teórico-metodológica de Norbert Elias, mobilizado pelas articulações que promove entre o conhecimento produzido em filosofia, medicina e sociologia, o artigo Memória e Odores: o debate entre biologia e sociologia em Norbert Elias como inspiração à compreensão dos usos sociais do olfato, de autoria de Salete Nery, intenta discutir os cheiros e o olfato, "potente acionador da memória", nas modulações históricas de seus usos e significados sociais. A autora problematiza o modo como a valoração social do sentido do olfato como inferior (primário) e, portanto, referido à animalidade dos seres humanos pode ter repercutido no lugar secundário a que o tema assumiu nas ciências biológicas enquanto objeto de investigação, mas também como tal inferiorização, presente em textos filosóficos e científicos de diferentes áreas, pode ter repercutido no modo de atenção aos cheiros, no uso do olfato e no mercado de fragrâncias. Deste modo, especula: Qual é o lugar dos cheiros e do olfato em nossas vidas? A relação com a memória é o eixo da discussão, e o objeto empírico é o consumo de perfumes.

Do mesmo modo, o questionamento a partir de ambivalências é o mote do texto Reconfigurações da nostalgia e do autêntico: memórias, patrimônios e tecnologias, de Marco Antônio de Almeida e Giulia Crippa. Partindo do tripé memória, patrimônio 
e tecnologia, os autores assumem como hipótese a dialética entre a recusa da tecnologia em nome de mecanismos entendidos como autênticos de recuperação e preservação da memória e o uso da tecnologia como possível recurso que permite o mesmo fim, no modo como a tecnologia é usada em diferentes espaços museais, o que possibilita, inclusive, a retomada de uma série de questões ligadas à relação tecnologia e arte, original e cópia, quando não a problematização da própria concepção de aura, atualizada ao mundo das redes tecnológico-informacionais.

Cabe, então, questionar a construção da noção de patrimônio, daquilo que pode e merece ser lembrado, e de sua relação com identidades enquanto pertencimentos afetivo-sociais que respeitam a determinados grupos. Este vetor de discussão é desenvolvido por Wilson Penteado Júnior ao levantar o lugar dos folcloristas na identificação das características e costumes que deveriam ser preservados/lembrados enquanto elementos discretos que funcionam como fonte à forja das nacionalidades, bem como seu clamor no sentido de registrar tais manifestações, segundo eles, em vias de extinção. É assim que autor vai acionar a documentação e análise dos folcloristas a respeito do jongo de São Paulo no artigo Folcloristas como intérpretes da nacionalidade: notas etnográficas sobre o jongo no "espetáculo da brasilidade" enquanto uma narrativa que se faz a partir de uma manifestação tomada, por sua vez, como uma narrativa de brasilidade.
Uma vez mais, em torno do tema da narratividade intrínseca às ciências sociais se desloca o interesse do texto assinado por Marisa Neres. Em Tempo, Memória, Narrativa e Teoria Sociológica, a autora se volta à tessitura mútua envolvendo memórias e narrativas na medida mesma em que ambas se fazem "matérias-primas" imprescindíveis entre si. O cotejo das concepções de Paul Ricoeur vem nos rastros do interesse, justamente, em considerar como a experiência do tempo está envolvida com a disposição da humanidade para compor relatos, assim, ajustando episódios que, a princípio, se sucedem e/ou se justapõem. A memória resulta, assim, na contrapartida necessária tanto da temporalização da experiência quanto dos desdobramentos dos exercícios de simbolização pelos quais o antes media o agora e, na conjunção de ambos, forjam-se as expectativas que acenam para o futuro. Com a interlocução estabelecida com Pierre Bourdieu, em segundo momento, a autora situa o tempo, a memória e a narrativa nos espaços sociais de possíveis e, com isto, requisita a natureza discursiva da sociologia para indagar a naturalidade adquirida por certos modelos teórico-analíticos acomodados no quadro desta mesma cultura disciplinar científica, no instante em que são consagrados ontologias do social.

A iniciativa de desnaturalização de modelos teóricos no contexto do quadro de raciocínio da sociologia conduz Thais Alves Marinho a levar ao lugar do pensando o edifício epistêmico definido pela depreciação da subjetividade como signo de um eu 
enclausurado, estando à contramão da circulação cultural dos saberes sócio-históricos e, portanto, encerrado nas sombras das emoções. Em Subjetividade e Memória Social: uma abordagem transdisciplinar, bem mais que se colocar o esforço de descontruir essa plataforma racionalista sobre a qual se ergueu o estatuto científico de verdade no ocidente, desde o advento do cartesianismo, a autora toma às mãos a tarefa de avançar na direção de um modelo analítico alternativo; o modelo que, ciente da sua vocação transdisciplinar, procura levar amiúde a intuição eliasiana de que as potencialidades humanas existem para se realizarem nas condições de interdependências e interpenetrações entre as pessoas. Logo, aproximando os conceitos de habitus (sociológico) e de "epigênese" (neurociência), à contramão da concepção linear e universalista de eu, o itinerário analítico-argumentativo do artigo insere a diversidade cultural como fator decisivo no delineamento de múltiplos perfis de subjetividade. E, ao mesmo tempo, deixa entrever o quão estreita pode ser a certeza em torno da disjunção razão e afetividade.

\section{Referências Bibliográficas}

ALVES, Elder P. M. A Economia Simbólica da Cultura Popular Sertanejo-Nordestina. Maceió: UFAL, 2011.

FARIAS, Edson. "Alguns apontamentos sobre o dueto memória e modernidade" IN: Elder P. Maia Alves (org.): Políticas Culturais para as Culturas Populares no Brasil Contemporâneo. Maceió: Edufal, 2011 